\title{
Research on the Deposit Insurance Pricing Under the Marketing RMB Interest Rate
}

\author{
Lingyan Sun ${ }^{1}$, Tianning Shi ${ }^{1}$, Panlu Shi ${ }^{1}$ \\ ${ }^{1}$ School of Science, Nanjing University of Science and Technology, Nanjing, China. \\ Correspondence: Lingyan Sun, School of Science, Nanjing University of Science and Technology, Nanjing, China.
}

Received: June 12, 2016

Accepted: July 1, 2016

Available online: July 7, 2016

doi:10.11114/afa.v2i2.1721

URL: http://dx.doi.org/10.11114/afa.v2i2.1721

\begin{abstract}
The deposit insurance pricing is the core issue of deposit insurance system, it determines the success or failure of the deposit insurance system in a way. In the current deposit insurance pricing methods, we treat the interest rates as a constant. With the interest rate marketization in China, the deposit insurance pricing methods have also changed accordingly. In this paper, we will give a functional representation of the impact of RMB interest rate marketization on interest rate by fitting the coefficients of the cubic function. Then we will use the data of 2013 to prove it. For the points that do not conform to this rule, we also have some explanations related to the major economic events at that time.
\end{abstract}

Keywords: marketization, interest rate, shibor, deposit insurance

\section{Introduction}

The deposit insurance system is an important economic system, is one of the important means to protect the healthy development of economy.There is a "hidden" deposit insurance system in China all the time, and the responsibility to protect the depositors is not only vague, but also very random. The establishment of the deposit insurance system is to institutionalize it and make it an open policy. The introduction of the deposit insurance system is not only the need to prevent the occurrence or spread of the banking crisis, but also the necessary requirement to improve the exit mechanism of the financial institutions.

The deposit insurance pricing is the core issue of deposit insurance system. At present, the more commonly used deposit insurance pricing models include the option pricing model and the expected loss pricing model. However, in the context of China's interest rate market, the establishment of a deposit insurance system will inevitably involve the impact of the marketization on interest rate. Therefore, we use the data of Shibor(Shanghai inter-bank offered rate) in 2014 and 2015 to get the optimal cubic function. And then use the coefficients of the two functions to do the fitting, so we can get the impact of the interest rate marketization. For the points that do not conform to this rule, we also have some explanations related to the major economic events at that time.

\section{Reasons for Choosing the Data of Shibor to Analyze}

\subsection{Definition}

The Shanghai Inter-bank Offered Rate (Shibor) is calculated, published and named by the inter-bank lending center in Shanghai as a technical platform. It is the arithmetic mean interest rate calculated from the Inter-bank Offered Rate which is offered by a group of banks with high credit rating.

\subsection{The Status and the Influence of Shibor}

Since it began in January 4, 2007, as a wholesale rate of the fund accommodation between commercial banks, Shibor has been a standard market rate. It is an important indicative interest rate in the financial market that can be a standard of pricing for the financial institutions.

\section{Data and Analysis}

\subsection{The Interpretation of Charts}

The following chart shows the image of the cubic function fitted by the data of 2014 and 2015 . We consider that the curve in the graph shows the impact of the marketization on interest rate. And we can use it to make a roughly forecast of the future interest rate. 
3.1.1 The constant term A



\begin{tabular}{|l|r|r|r|}
\hline Equation & $y=1 /\left(a+b^{\star} x\right)$ & & \\
\hline Adj. R-Square & 0.23137 & & \\
\hline $15 A$ & & Value & Standard Error \\
\hline $15 A$ & a & 1.35368 & 0.36639 \\
\hline
\end{tabular}

Figure 1. The image of the fitting function with constant coefficient in 2014 and 2015

Table 1. The Specific Data of the Constant Coefficient

\begin{tabular}{|c|c|c|c|c|c|c|}
\hline Month & January & February & March & April & May & June \\
\hline 2014 & 3.60013 & 3.05451 & 2.58056 & 2.78917 & 2.68793 & 2.67272 \\
\hline 2015 & 4.52714 & 3.08556 & 3.41942 & 3.10083 & 1.83025 & 1.07714 \\
\hline Month & July & August & September & October & November & December \\
\hline 2014 & 2.90544 & 3.25976 & 2.86646 & 2.41502 & 2.60807 & 2.91447 \\
\hline 2015 & 1.14764 & 1.50858 & 1.90847 & 1.96474 & 1.79636 & 1.80926 \\
\hline
\end{tabular}




\subsubsection{Other Coefficients}

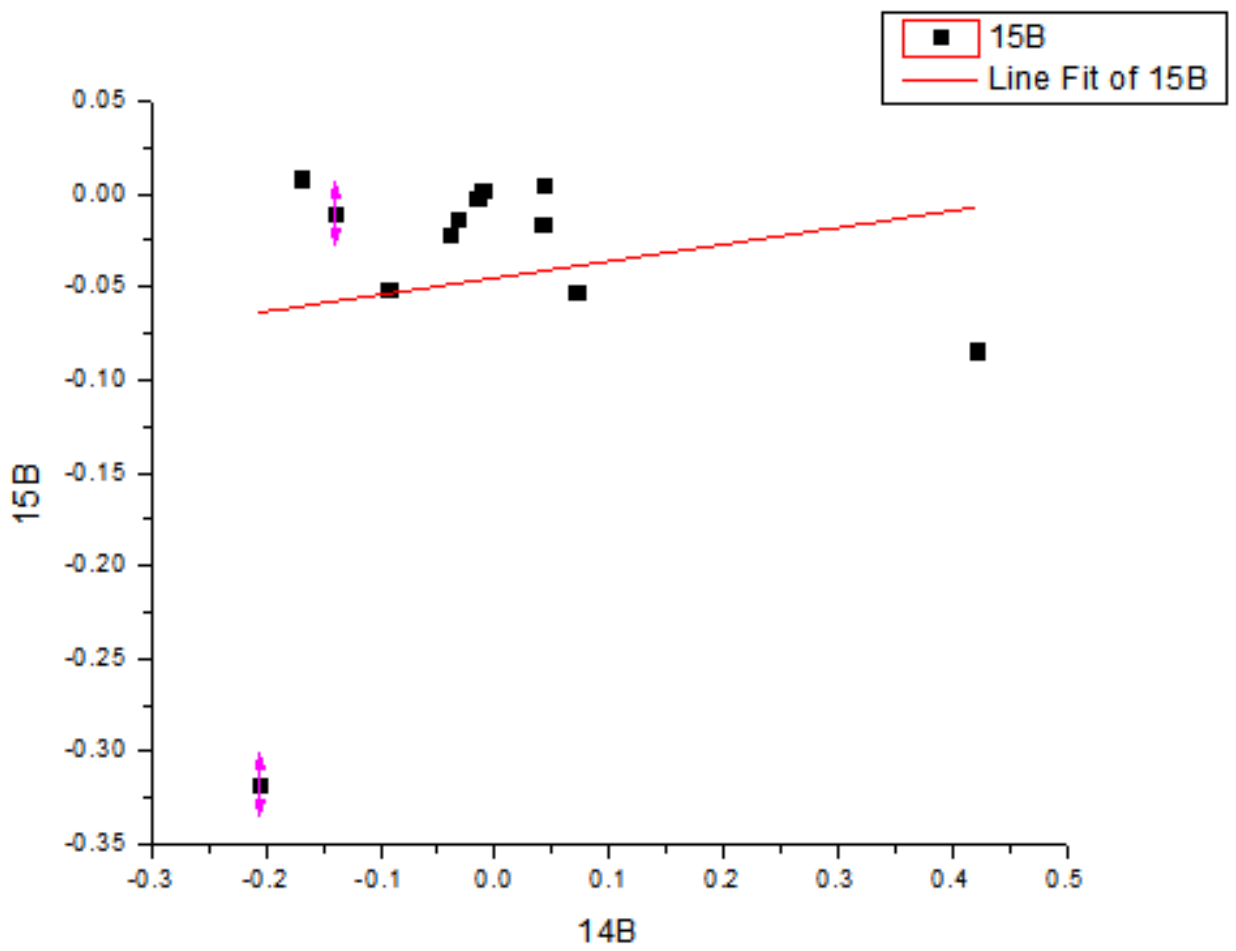

\begin{tabular}{|c|c|c|c|}
\hline Equation & $y=A+B^{*} x$ & & \\
\hline Adj. R-Square & -0.0711 & & \\
\hline & & Value & Standard Error \\
\hline $15 B$ & A & -0.04503 & 0.02694 \\
\hline $15 B$ & B & 0.09019 & 0.17365 \\
\hline
\end{tabular}

Figure 2-1 The image of the fitting linear function in 2014 and 2015

Table 2-1. The specific data of the linear function coefficients

\begin{tabular}{|r|c|c|c|c|c|c|}
\hline \multicolumn{1}{|l|}{ Month } & January & February & March & April & May & June \\
\hline 2014 & -0.2059 & 0.42158 & -0.16995 & 0.07123 & -0.09337 & -0.03861 \\
\hline 2015 & -0.31765 & -0.08382 & 0.0086 & -0.05252 & -0.05125 & -0.02167 \\
\hline Month & July & August & September & October & November & December \\
\hline 2014 & 0.04289 & -0.03326 & -0.01105 & 0.04195 & -0.01583 & -0.13952 \\
\hline 2015 & 0.00499 & -0.01305 & 0.00217 & -0.01567 & -0.00204 & -0.01012 \\
\hline
\end{tabular}




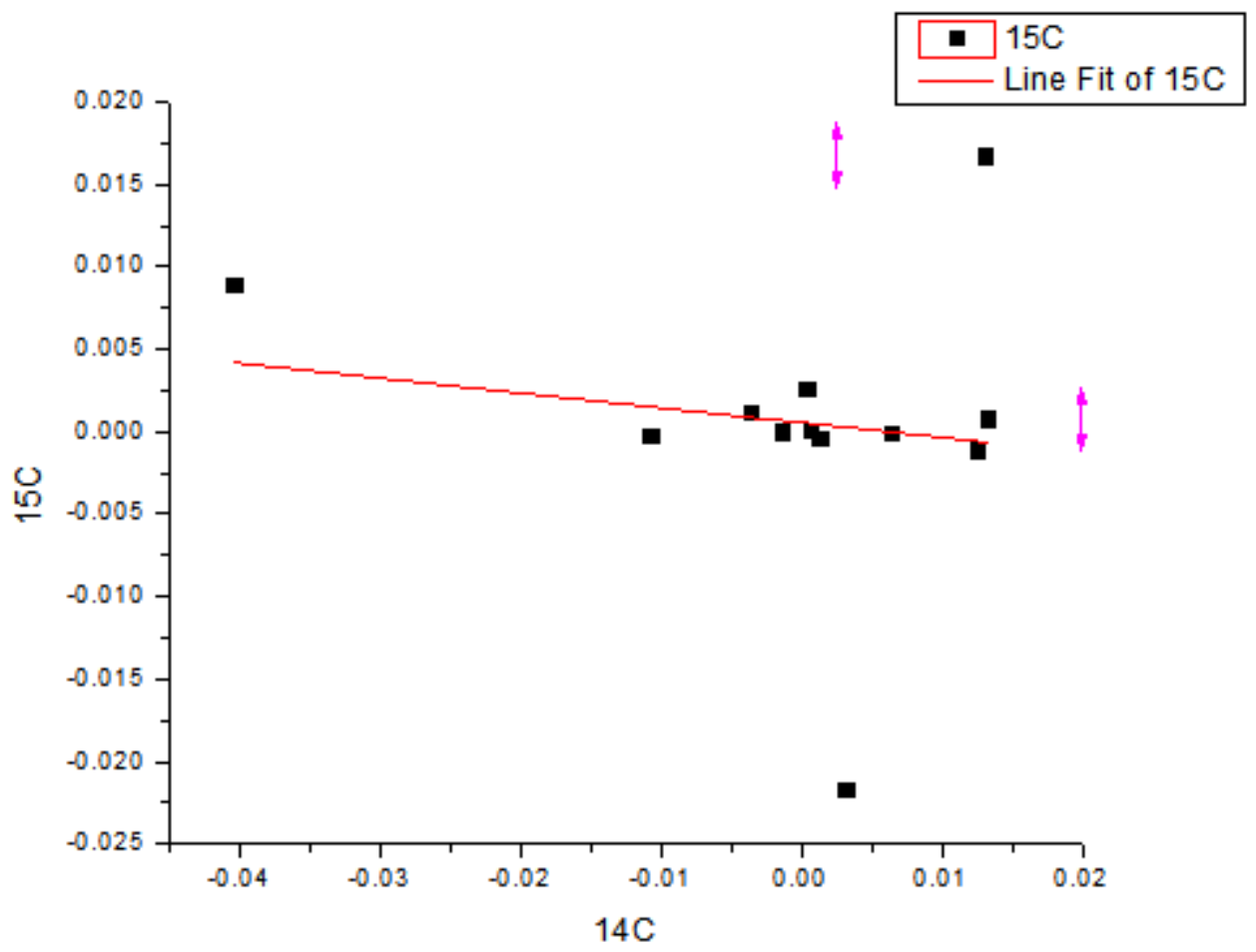

\begin{tabular}{|c|c|c|c|}
\hline Equation & $y=A+B^{*} x$ & & \\
\hline Adj. R-Square & -0.07503 & & \\
\hline & & Value & Standard Error \\
\hline $15 \mathrm{C}$ & A & $5.49066 \mathrm{E}-4$ & 0.00261 \\
\hline $15 \mathrm{C}$ & B & -0.09052 & 0.18781 \\
\hline
\end{tabular}

Figure 2-2. The image of the fitting quadratic function in 2014 and 2015

Table 2-2. The Specific Data of the Quadratic Function Coefficients

\begin{tabular}{|c|c|c|c|c|c|c|}
\hline Month & January & February & March & April & May & June \\
\hline 2014 & 0.0131 & -0.04041 & 0.0125 & -0.01073 & 0.0064 & 0.00315 \\
\hline 2015 & 0.01678 & 0.00892 & -0.00105 & $-2.58045 \mathrm{E}-04$ & $-4.74392 \mathrm{E}-05$ & -0.02167 \\
\hline $\begin{array}{c}\text { Month } \\
\text { Year }\end{array}$ & July & August & September & October & November & December \\
\hline 2014 & -0.00139 & 0.000328584 & 0.00126 & -0.0036 & 0.000632389 & 0.01331 \\
\hline 2015 & $3.20268 \mathrm{E}-05$ & $2.61000 \mathrm{E}-03$ & $-3.65259 \mathrm{E}-04$ & $1.24000 \mathrm{E}-03$ & $9.96056 \mathrm{E}-05$ & $7.91127 \mathrm{E}-04$ \\
\hline
\end{tabular}




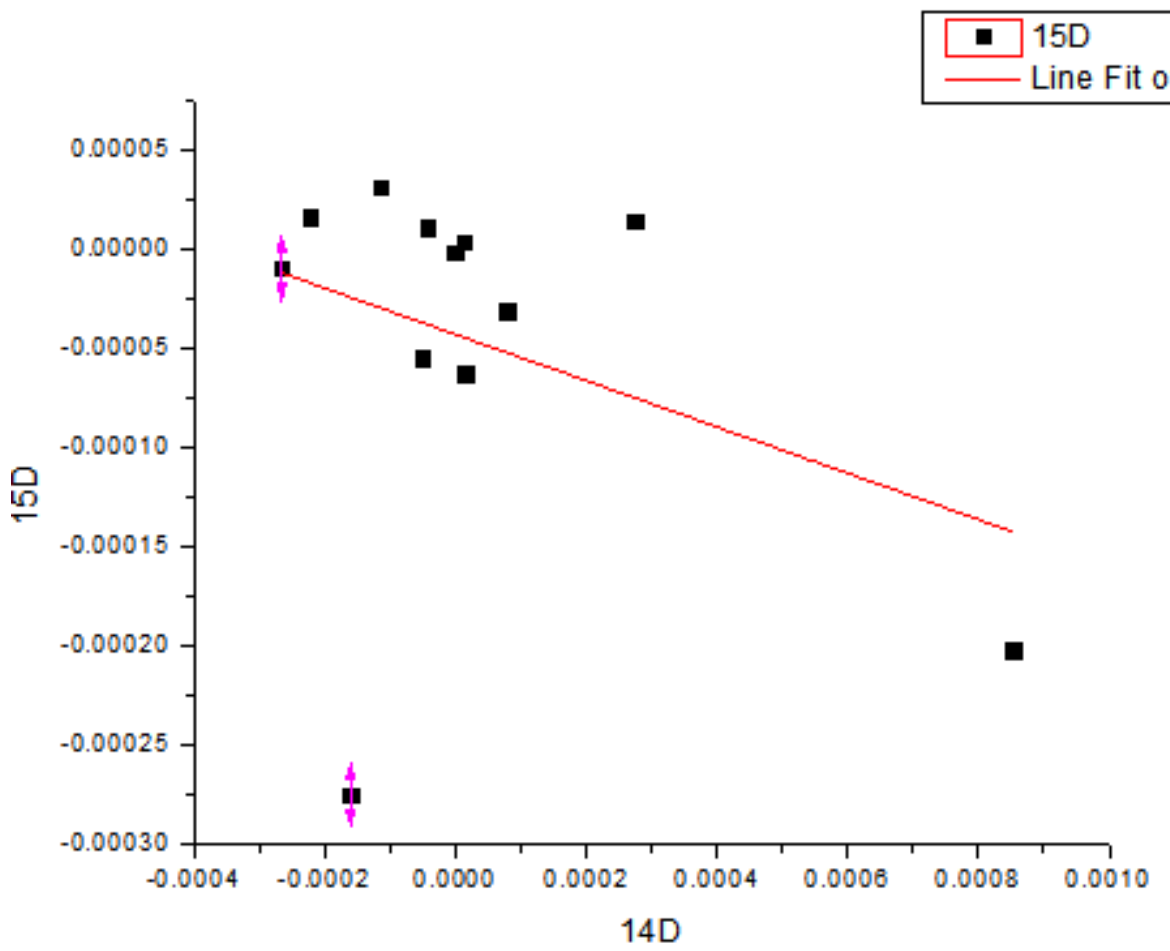

\begin{tabular}{|l|r|r|r|}
\hline Equation & $y=A+B^{\star} x$ & & \\
\hline Adj. R-Square & 0.04432 & & \\
\hline & & Value & Standard Error \\
\hline 15D & A & $-4.28492 E-5$ & $2.70308 E-5$ \\
\hline 15D & B & -0.11664 & 0.09492 \\
\hline
\end{tabular}

Figure 2-3. The image of the fitting cubic function in 2014 and 2015

Table 2-3. The Specific Data of the Cubic Function Coefficients

\begin{tabular}{|c|c|c|c|c|c|c|}
\hline Month & January & February & March & April & May & June \\
\hline 2014 & $-1.62019 \mathrm{E}-04$ & $8.52403 \mathrm{E}-04$ & $-2.22775 \mathrm{E}-04$ & $2.73710 \mathrm{E}-04$ & $-1.16183 \mathrm{E}-04$ & $-5.07867 \mathrm{E}-05$ \\
\hline 2015 & $-2.74533 \mathrm{E}-04$ & $-2.01675 \mathrm{E}-04$ & $1.66170 \mathrm{E}-05$ & $1.48101 \mathrm{E}-05$ & $3.14136 \mathrm{E}-05$ & $-5.46095 \mathrm{E}-05$ \\
\hline $\begin{array}{c}\text { Month } \\
\text { Year }\end{array}$ & July & August & September & October & November & December \\
\hline 2014 & $1.12577 \mathrm{E}-05$ & $1.33153 \mathrm{E}-05$ & $-4.27225 \mathrm{E}-05$ & $7.80389 \mathrm{E}-05$ & $-2.56095 \mathrm{E}-06$ & $-2.67360 \mathrm{E}-04$ \\
\hline 2015 & $4.23777 \mathrm{E}-06$ & $-6.23951 \mathrm{E}-05$ & $1.12939 \mathrm{E}-05$ & $-3.10462 \mathrm{E}-05$ & $-1.40370 \mathrm{E}-06$ & $-9.39615 \mathrm{E}-06$ \\
\hline
\end{tabular}

Combined with the above charts, we can know that the deviations of the coefficient $\mathrm{C}, \mathrm{B}, \mathrm{D}$ are very small. With the impact of Shibor in the final results, we can see that the small deviations of B, C, D can be ignored. 


\section{The Analytic Method of Outliers}

\subsection{All the Special Events of Two Years Should Be Considered}

If we only analyse the outliers of 2014, then the data we got before interest rate marketization should all result the real data of 2015, it is obviously wrong. So when we analyse the influence of interest rate marketization on interest rate, the special events of 2015 should be considered too.

\subsection{Illustrating the Specific Analysis Method with Examples}

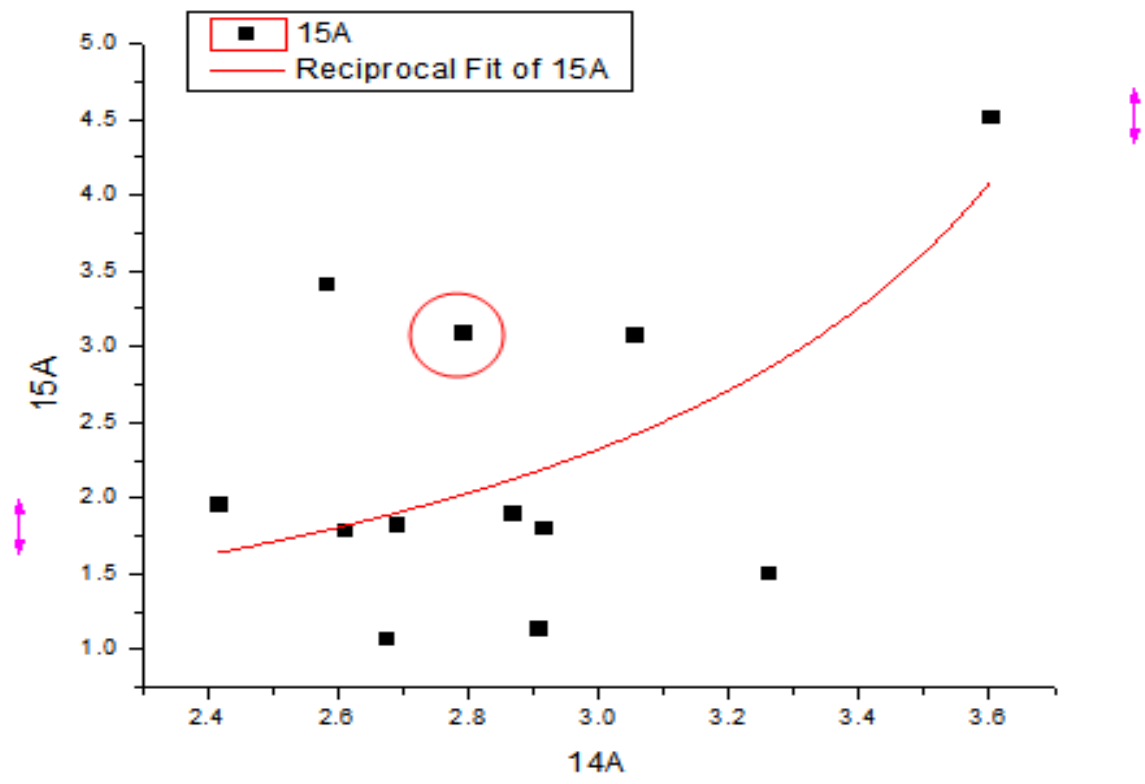

Figure 1-1 The image of the fitting function with constant coefficient in 2014 and 2015

Consider the point in the red circle as an example, it is the fitting point of March. When determine the impact of special events on this outlier in March 2015, we should compare the y value of the crossover point and the outlier. Obviously, the value of outliers is larger. It shows that the special events of 2015 make the fitting point of this month being larger. So in analysis we should find out the special events that make the interest rate rise in March 2015. The same, when determine the impact of special events on this outlier in March 2014, we can get that the value of outlier is smaller. Then in analysis we should find out the special events that reduce the interest rate in March 2014.

Which is need to be explained is, although all the special events of two years should be considered, it does not mean that all the events have an impact on the outliers. A event with sufficient strength is enough to influence the point, so the following analysis is focusing on the special events that make the image changed. We do not consider this situation that the fit points maybe are influenced by two special events that cancel each other out. Because we can not find out the specific formulas or figures to compare the influences.

\section{The Analysis of Abnormal Months}

\subsection{The Abnormal Month}

According to the graph 1, after moving this curve, combining with the table 1 we can know that there are seven abnormal months. The points of January, February, March, April are over the curve, and the points of June, July and August are under the curve.

\subsection{The Events Resulting in Abnormal Interest Rates in 2015}

The data of January 2015 is affected by December 2014. January 2015 is the first month to open the interest rate market, so the increase in the amount of financial products in December 2014 would have impact on the interest rates in January 2015. The unbalanced demand and supply of currency in the interest rates did not get due when the market changes, so it directly reflected in the interest rate fluctuations in 2015. 


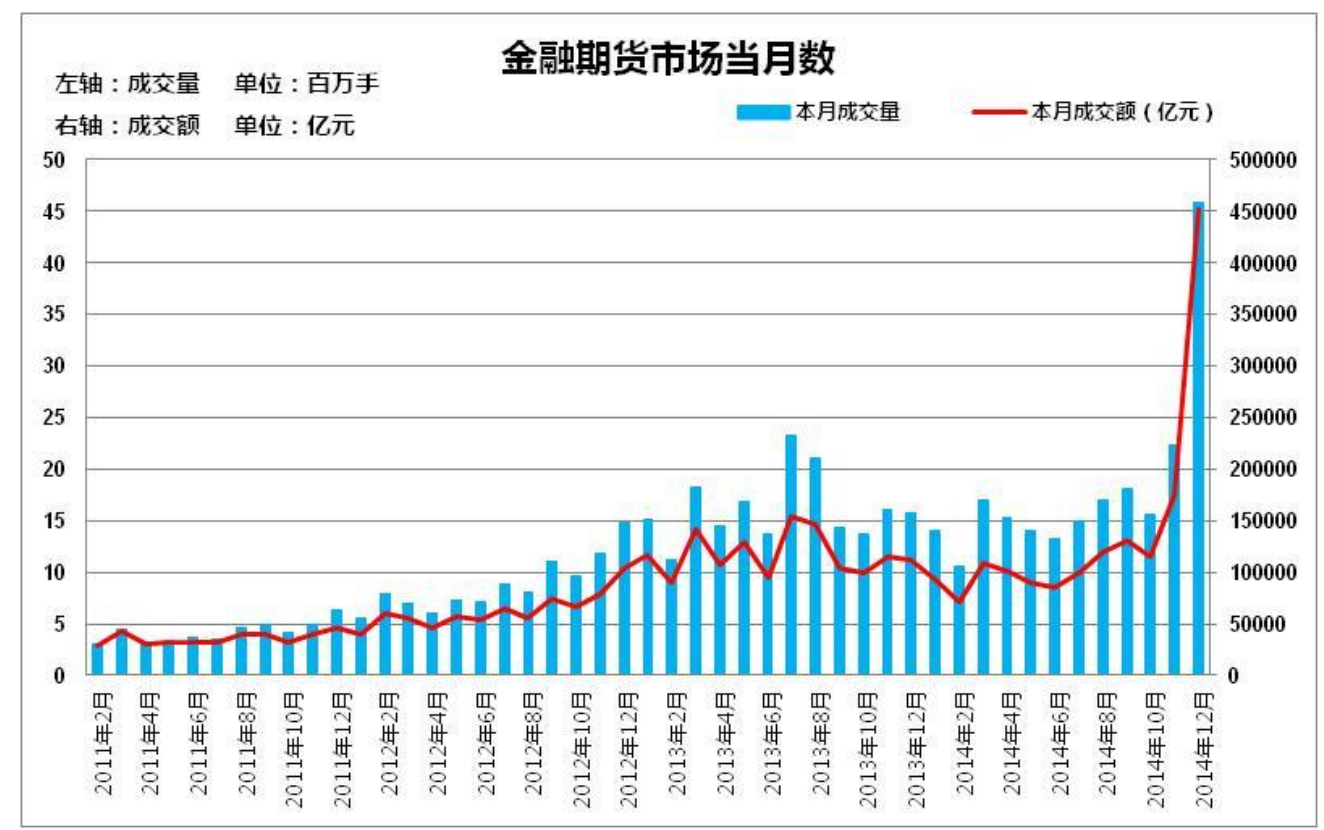

Figure 3. The trading volume in financial futures market

In March 2015, the turnover of Shanghai and Shenzhen in two days has been refreshed repeatedly. The index is also rising, especially in the growth enterprise markets and Small and Medium Board. But after June 12th the Shanghai Composite Index hit a high of 5178 points, it fell by more than $45 \%$ within two months. The phenomenon that thousands of stocks limiting down also happened in June, July and August.

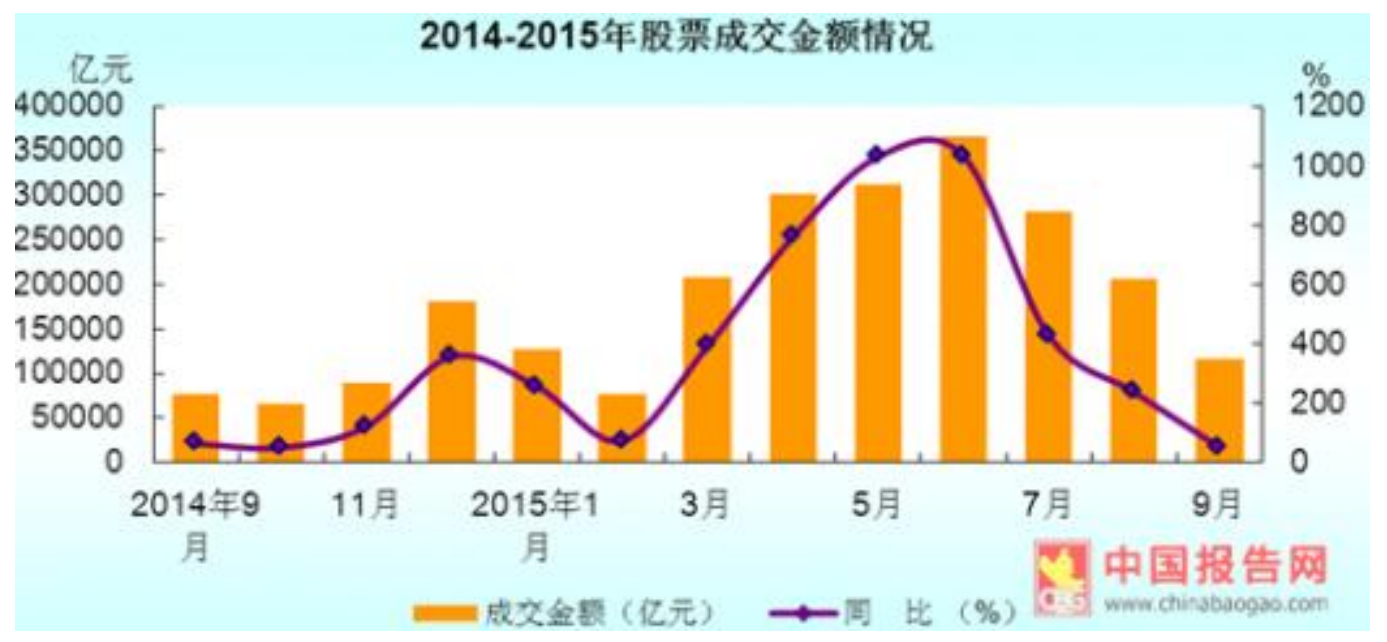

Figure 4. The transaction amount in stock market in 2014 and 2015 




Figure 5. The Dollar Currency Rate in 2015

The financial futures turnover showed a surge in trading volume of financial products in December 2014, the demand for currency increased, the interest rates in January 2015 are kind of high. It is very obvious in the figure 4 that the trading volume of stock market increased rapidly in February to March 2015, the demand for currency also increased, so the interest rates in February and March are high. Conversely, the trading volume of stock market decreased in June, July and August, so the interest rates are low. According to the figure 5, the surge of the exchange rate in August 2015 made the foreign investment flooding in, then the bank deposits decreased and the interest rates in August are high.

\subsection{The Effect of Special Events on Some Abnormal Months in 2014}

\subsubsection{Analysis for January to April}

The recession of industries including real estate and steel trade reduced the volume of transactions. The decrease in the amount of the transaction made the market demand for currency lower, so the interest rates in January to April are low. In March the government encouraged the grass-roots entrepreneurs and March $3^{\text {rd }}$ is the first working day after the reform of the registered capital registration system in our country, so the banks decreased the interest rates to encourage enterprises to carry out loans. The increase in the loan amounts can explain that the rate in April of deviation is lower than in March, the market demand for currency increased and the interest rates rose. However, the overall rate of interest rates from January to April are low, so although there is a rebound in April, the rates are still low.

\subsubsection{Analysis for June to August}

In order to encourage financial institutions to improve the allocation for supporting the"Three Agriculture" and small enterprises in the field of loan ratio and enhance the ability of financial services to the real economy, the People's Bank of China forced the targeted cuts to required reserve ratios in June 16, 2014.

It made a tendency to lower the interest rates in June to August.

\subsubsection{Other influencing factors}

There is a round of helping deposits at the end of the season in the entire commercial banking system of China. Starting in 2014, this situation exacerbated: the deposit at the end of January is less than the end of last year, the deposit at the end of March is more than the end of February and so on. Until November 6, 2014, the measures for the management of deposit deviation is introduced, this phenomenon began disappearing.

These banking industry laws can explain the deflection of monthly interest rate to some extent, but we do not have the data to show how the interest rate changes, so we can not know which month is influenced by these phenomenons.

\section{Inspect}

Next, we will fit the data of 2013 and 2015, test the results with the above methods. 


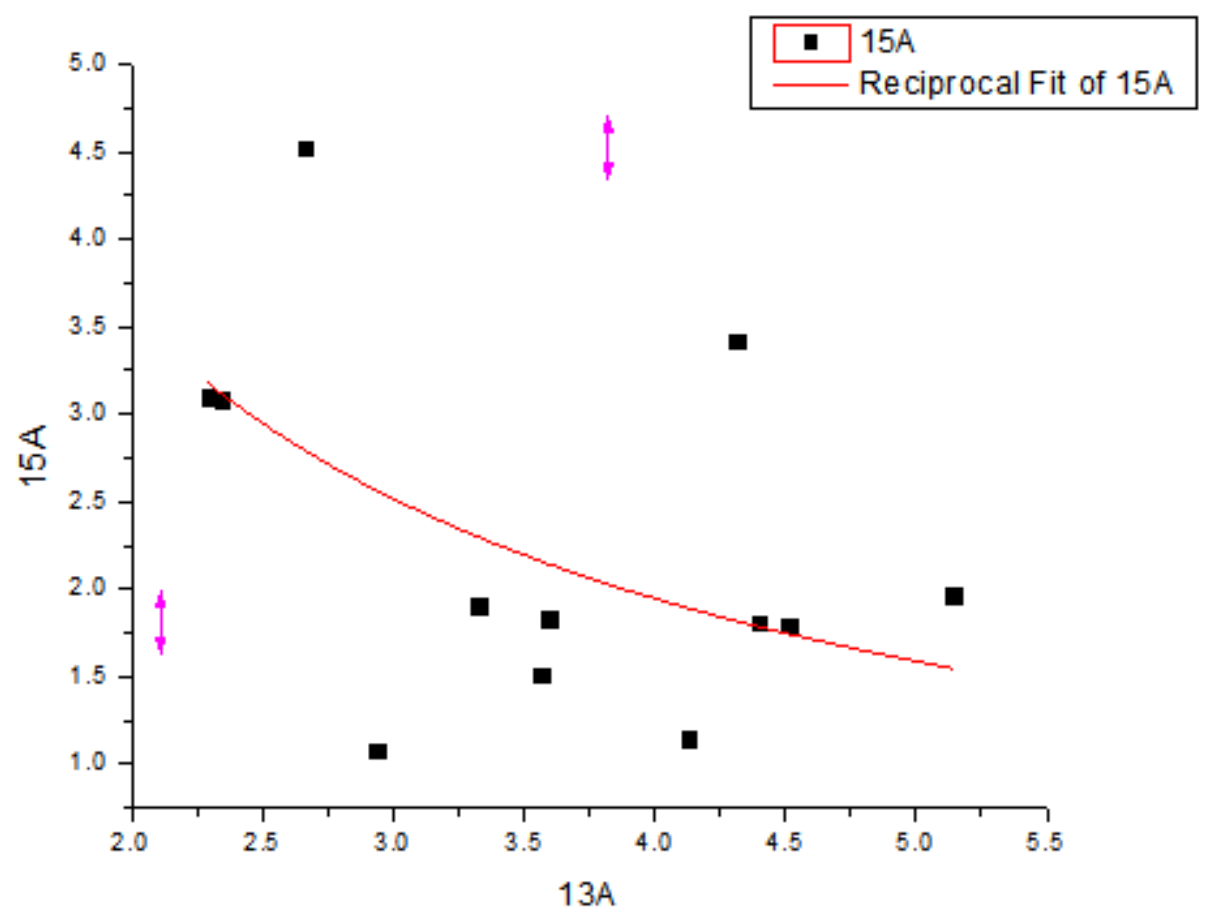

\begin{tabular}{|l|r|r|r|}
\hline Equation & $y=1 /\left(a+b^{\star} x\right)$ & & \\
\hline Adj. R-Square & 0.14848 & & \\
\hline & & Value & Standard Error \\
\hline $15 A$ & a & 0.04884 & 0.19468 \\
\hline $15 A$ & b & 0.1162 & 0.06585 \\
\hline
\end{tabular}

Figure 6. The image of the fitting function with constant coefficient in 2013 and 2015

Table 3. The specific data of the constant coefficient

\begin{tabular}{|c|c|c|c|c|c|c|}
\hline Month & January & February & March & April & May & June \\
\hline 2015 & 4.52714 & 3.08556 & 3.41942 & 3.10083 & 1.83025 & 1.07714 \\
\hline 2013 & 2.66249 & 2.33978 & 4.31269 & 2.29027 & 3.59352 & 2.93463 \\
\hline Month & July & August & September & October & November & December \\
\hline 2015 & 1.14764 & 1.50858 & 1.90847 & 1.96474 & 1.79636 & 1.80926 \\
\hline 2013 & 4.12674 & 3.56583 & 3.32519 & 5.14162 & 4.51333 & 4.39851 \\
\hline
\end{tabular}


According to the table 3 and the figure 6, we can see that January, March, May, June, July, August, September and October are abnormal months.

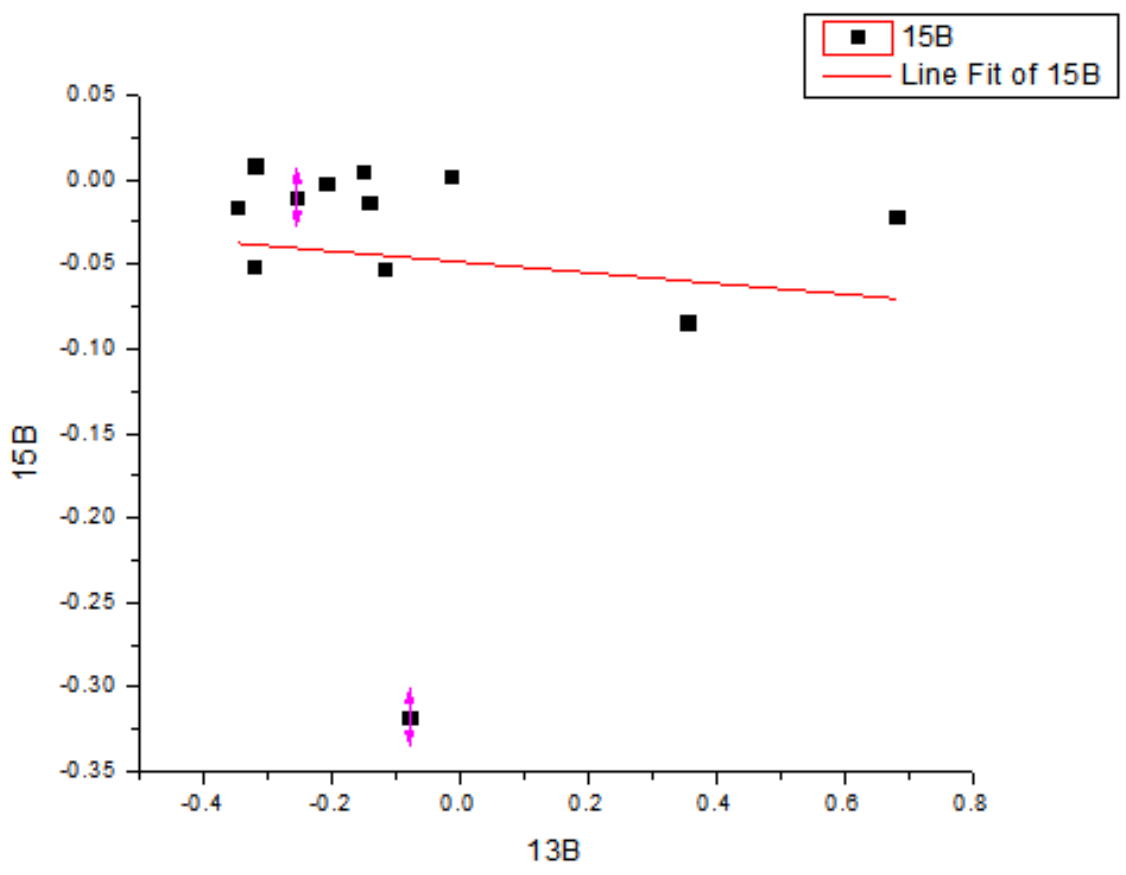

\begin{tabular}{|l|r|l|r|}
\hline Equation & $\mathrm{y}=\mathrm{A}+\mathrm{B}^{*} \mathrm{x}$ & & \\
\hline Adj. R-Square & -0.08723 & & \\
\hline & & Value & Standard Error \\
\hline $15 \mathrm{~B}$ & $\mathrm{~A}$ & -0.04843 & 0.02799 \\
\hline $15 \mathrm{~B}$ & $\mathrm{~B}$ & -0.03186 & 0.09296 \\
\hline
\end{tabular}

Figure 7-1 The image of the fitting linear function in 2013 and 2015

Table 4-1. The specific data of the linear function coefficients

\begin{tabular}{|c|c|c|c|c|c|c|}
\hline \multicolumn{1}{|c|}{ Jonth } & January & February & March & April & May & June \\
\hline 2015 & -0.31765 & -0.08382 & 0.0086 & -0.05252 & -0.05125 & -0.02167 \\
\hline Month & -0.0779 & 0.35547 & -0.31841 & -0.11852 & -0.32121 & 0.68241 \\
\hline 2015 & July & August & September & October & November & December \\
\hline 2013 & -0.00499 & -0.01305 & 0.00217 & -0.01567 & -0.00204 & -0.01012 \\
\hline
\end{tabular}


According to the table 4-1 and the figure 7-1, we can see that January is an abnormal month.



\begin{tabular}{|l|r|r|r|}
\hline Equation & \multicolumn{1}{|c|}{$\mathrm{y}=\mathrm{A}+\mathrm{B}^{*} \mathrm{x}$} & & \\
\hline Adj. R-Square & -0.09828 & & \\
\hline & & Value & Standard Error \\
\hline $15 \mathrm{C}$ & $\mathrm{A}$ & $4.5252 \mathrm{E}-4$ & 0.00286 \\
\hline $15 \mathrm{C}$ & $\mathrm{B}$ & 0.01022 & 0.08165 \\
\hline
\end{tabular}

Figure 7-2. The image of the fitting quadratic function in 2013 and 2015

Table 4-2. The specific data of the quadratic function coefficients

\begin{tabular}{|c|c|c|c|c|c|c|}
\hline Month & January & February & March & April & May & June \\
\hline 2015 & 0.01678 & 0.00892 & -0.00105 & $-2.58045 \mathrm{E}-04$ & $-4.74392 \mathrm{E}-05$ & -0.02167 \\
\hline 2013 & 0.00253 & -0.04074 & 0.01416 & 0.1022 & 0.02219 & -0.0241 \\
\hline Month & July & August & September & October & November & December \\
\hline 2015 & $3.20268 \mathrm{E}-05$ & $2.61000 \mathrm{E}-03$ & $-3.65259 \mathrm{E}-04$ & $1.24000 \mathrm{E}-03$ & $9.96056 \mathrm{E}-05$ & $7.91127 \mathrm{E}-04$ \\
\hline 2013 & 0.00616 & 0.01234 & 0.01437 & 0.01601 & 0.01658 & 0.01997 \\
\hline
\end{tabular}


According to the table 4-2 and the figure 7-2, we can see that January, February, June are abnormal months.



\begin{tabular}{|c|c|c|c|}
\hline Equation & $y=A+B^{*} x$ & & \\
\hline Adj. R-Square & 0.29062 & & \\
\hline & & Value & Standard Error \\
\hline $15 \mathrm{D}$ & A & $-5.94898 \mathrm{E}-5$ & 2.38193E-5 \\
\hline $15 \mathrm{D}$ & B & -0.13909 & 0.05927 \\
\hline
\end{tabular}

Figure 7-3. The image of the fitting cubic function in 2013 and 2015

Table 4-3. The specific data of the cubic function coefficients

\begin{tabular}{|c|c|c|c|c|c|c|}
\hline Month & January & February & March & April & May & June \\
\hline 2015 & $-2.74533 \mathrm{E}-04$ & $-2.01675 \mathrm{E}-04$ & $1.66170 \mathrm{E}-05$ & $1.48101 \mathrm{E}-05$ & $3.14136 \mathrm{E}-05$ & $-5.46095 \mathrm{E}-05$ \\
\hline 2013 & $-5.99915 \mathrm{E}-05$ & $1.09000 \mathrm{E}-03$ & $-2.05337 \mathrm{E}-04$ & $-1.63796 \mathrm{E}-04$ & $-3.78655 \mathrm{E}-04$ & $8.90322 \mathrm{E}-05$ \\
\hline $\begin{array}{c}\text { Month } \\
\text { Year }\end{array}$ & July & August & September & October & November & December \\
\hline 2015 & $4.23777 \mathrm{E}-06$ & $-6.23951 \mathrm{E}-05$ & $1.12939 \mathrm{E}-05$ & $-3.10462 \mathrm{E}-05$ & $-1.40370 \mathrm{E}-06$ & $-9.39615 \mathrm{E}-06$ \\
\hline 2013 & $5.46413 \mathrm{E}-05$ & $-2.82200 \mathrm{E}-04$ & $-3.25937 \mathrm{E}-04$ & $-1.61662 \mathrm{E}-04$ & $-3.64044 \mathrm{E}-04$ & $-4.22168 \mathrm{E}-04$ \\
\hline
\end{tabular}

According to the table 4-3 and the figure 7-3, we can see that January is an abnormal month.

\subsection{The analysis of abnormal month}

6.2.1 The analysis of abnormal situation in January

According to the figure 7-3 and table 4-3, we can see that the four coefficients in January are all very abnormal, it is regular that the influence of the coefficients are on the same deviation between January 2013 and January 2015 . Only the constant coefficients show that the interest rate is high, and the other coefficients show that the interest rate is low. 
That is to say, the occurrence of conclusive events decrease the interest rates, and the occurrence of unexpected events to increase interest rates. The reasons are multiple, first of all, the impact of the 2015 on the fitting of the data also influenced the fitting of 2013 and 2015, and the data of January are less than other months. What is more, there are many new policies enacted in January 2013 and December 2012. It also had a greater impact on interest rates. In December 5, 2012, the Phoenix reported that the people's Bank of China reduced the poundage of credit cards. The poundage in restaurant and entertainment business down from the original $2 \%$ to $1.25 \%$, it is a 37.5 per cent drop. It is estimated that by the impact of credit card fees down, the bank card fee income of the four major state-owned banks may be reduced by 6 billion yuan a year. Therefore, on the one hand banks should encourage consumers to use credit cards, on the other hand should increase the credit card issuance to get more functionality like mobile banking and third-party payment. So at the end of 2012 when the news released, the bank would cooperate with businesses to prompt consumers handing cards. These measures are mostly that consumers can receive a benefit by using a certain kind of bank card, which from the side also stimulated the economy and prompted the interest rates rising.

In January 8, 2013, the National Development and Reform Commission issued a notice to adjust the maximum retail price of drugs from February 1, 2013. Most of these drugs are commonly used in clinical medicine, the average reduction is $15 \%$, of which the average reduction of high priced drugs is $20 \%$.

The executive meetings of the State Council decided to continue improving the basic pension for enterprise retirees. It is increased by $10 \%$ according to the monthly basic pension in 2012 .

For the old people, the medical expenses are the main expenses and the pension is the main source of finance. Because of the adjustment of drug price and pension, they would put the money in the bank or buy government bonds to prompt the interest rates decreasing.

There are a large number of new policies in January and the date is special so the deviations of data are large. And there are no specific models and formulas for the impact on interest rates, because the implementation of various policies at the same time made the non-constant terms abnormal. The data show that these policies made interest rates low. It is consistent with the national macroeconomic polices in 2013, that is, reducing the interest rates to promote the development of the real economy. The unexpected event may be the trading volume surge of financial derivatives at the end of 2014. It had a huge impact on the data of January 2015. Due to the complexity of the events in January, the data of February and March are affected to be abnormal.

6.2.2 The analysis of abnormal situation in other months

Observing the constant terms, we can see that the occurrence of some events led to low interest rates in June, July, August, September of 2013 and 2015. The data of quadratic terms show that some events promoted the interest rates increasing in June,2013. The special events in 2015 had already been explained, so we analyse the events in 2013 below.

In May 15th, the State Council issued a decision that canceling and decentralizing 117 items of administrative examination and approval. According to statistics, these 117 items are concentrated in the economic field mainly investment and production activities. The aim is to minimize the government intervention so that the "invisible hand" of market can be more effective.

In June 23rd, the central bank proposed to do preset and fine-tune timely and appropriately. The central bank indicated that it would pay attention to the latest trends in finance and the changes of international capital flows, and continue the prudent monetary policy.

In June $25^{\text {th }}$, the central bank relieved the shortage of currency and promised to provide financial support to the banks that meet the conditions. The central bank said that it had provided support to some financial institutions in order to make the currency market running steadily. Some banks that have sufficient liquidity also began to play the role of stabilizer in the market, and the interest rates have been steady. In June 25th, the overnight pledged repo interest rate has dropped to $5.83 \%$, dropped 592 basic points.

In August, the State Council issued the implementing opinions of financial support for developing small and micro enterprise. It proposed supporting measures made arrangements from eight aspects, including ensuring the growth and increment of small and micro enterprises loans, effectively reduce the financing costs and so on.

In September 29, 2013, the Shanghai pilot free trade zone was officially established. The main contents of the project including accelerating the transformation of government functions, expanding the investment field, speeding up the transformation of the mode of trade development, deepening the innovation in the financial field and establishing a regulatory environment to adapt to the experimental area.

It is not difficult to see from the above facts that the business increased in May and June, and the currency in the market raised so the interest rate should be high. But the national policy is to maintain the currency market steady and 
encourage the development of small and medium enterprises, it made the constant terms showing the interest rate is low when the quadratic terms showing it is high in May and June in 2013. That is because the market interest rate itself is high but the strong intervention made this data abnormal. In October, influenced by the free trade area, the circulating capital in market increased and the interest rate is high naturally. The constant terms of March, May, July, August, September, October are low, because these policies affected the interest rate from the side. And the events are not as complicated as them in January, so only the constant terms are abnormal.

\section{Summary}

According to this method, you just need to have any complete figure of one year's interest rate without interest rate liberalization. Then you eliminate the effects of important economic events in that year, and use the function above to get a new function of any approximate interest rate after one year's interest rate liberalization and time. Adding the effects of some unknown important economic events which probably happen in this year to the interest rate, you can approximately get the real interest rate with the function. That is to say, you can forecast the interest rate in the future and then fix a price of deposit insurance with B-S model. The difficult in the application of this article is that there is no quantization standard of the effects of important economic events to function coefficient and the timeliness of economic events can't be quantified. So the analyses can only illustrate the tendency of the events' effects to the interest rate but not the specific size and aging time. In addition, the change of interest rate is related to national economic policy and current strategies, and the big background has an enormous impact on the overall trend of interest rate before liberalization. Besides, the time, methods and the strength of the measures taken by country are, to some degree, influential in interest rate. The method of this article can compute roughly the function of unknown years' interest rates and time. Further studies need to classify the events which can probably have impact on interest rates, and show the specific quantization of the events' effects to function coefficient through a large number of data and events observation.

\section{References}

Jiang, L. S. (2008). Mathematical models and methods of option pricing Second Edition [M]. Beijing: Higher Education Press.

Jiang, L. S., \& Xu, C. L. (2013). Mathematical model and case analysis of financial derivatives pricing Second Edition [M]. Beijing: Higher Education Press.

Ma, J. (2006). Interest rate and exchange rate risk management [M]. Beijing: The People's Posts and Telecommunications Press.

Tang, M. Q. (2010). Research on deposit insurance system -- Design of Chinese deposit insurance system [D]. Beijing: China Financial Publishing House.

Wang, T. Y. (2014). Research on the interest rate liberalization of small and medium sized banks under the new normal [M]. Beijing: China Financial Publishing House.

Zhang, C. L. (2016). The empirical analysis for the price of Chinese treasury bond future under the interest rate market [M]. Nanjing: Nanjing University of Science \& Technology.

Zhuo, X. (2013). Research on the interest rate liberalization [M]. Beijing: China Development Press.

\section{$(\mathrm{cc}) \mathrm{BY}$}

This work is licensed under a Creative Commons Attribution 3.0 License. 